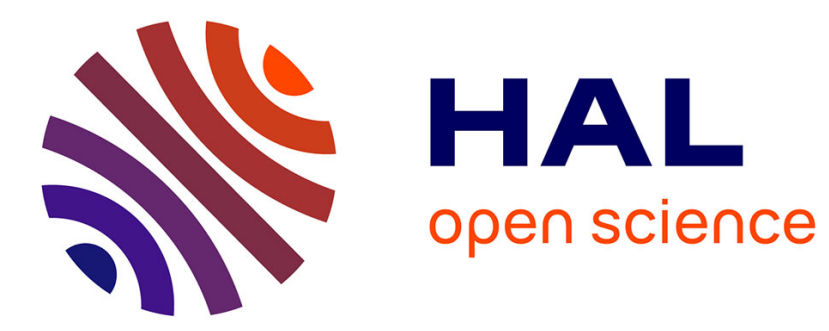

\title{
Involvement of caveolin-1 and CD36 in native LDL endocytosis by endothelial cells
}

Marie-Christine Gerbod-Giannone, Laurence Dallet, Grégoire Naudin, Annelise Sahin, Marion Decossas, Sylvie Poussard, Olivier Lambert

\section{- To cite this version:}

Marie-Christine Gerbod-Giannone, Laurence Dallet, Grégoire Naudin, Annelise Sahin, Marion Decossas, et al.. Involvement of caveolin-1 and CD36 in native LDL endocytosis by endothelial cells. Biochimica et Biophysica Acta (BBA) - General Subjects, 2019, 1863 (5), pp.830-838. 10.1016/j.bbagen.2019.01.005 . hal-02346733

\section{HAL Id: hal-02346733 \\ https://hal.science/hal-02346733}

Submitted on 13 Jul 2021

HAL is a multi-disciplinary open access archive for the deposit and dissemination of scientific research documents, whether they are published or not. The documents may come from teaching and research institutions in France or abroad, or from public or private research centers.
L'archive ouverte pluridisciplinaire HAL, est destinée au dépôt et à la diffusion de documents scientifiques de niveau recherche, publiés ou non, émanant des établissements d'enseignement et de recherche français ou étrangers, des laboratoires publics ou privés. 


\section{Involvement of Caveolin-1 and CD36 in native LDL endocytosis by endothelial cells}

Marie-Christine Gerbod-Giannone*, Laurence Dallet, Grégoire Naudin, Annelise Sahin, Marion Decossas, Sylvie Poussard, and Olivier Lambert

Institute of Chemistry and Biology of Membranes and Nano-objects (CBMN), UMR 5248, CNRS, University of Bordeaux, INP, F-33600 Pessac, France.

*corresponding author: mc.gerbodgiannone@cbmn.u-bordeaux.fr 


\begin{abstract}
Atherosclerosis is a lipid disease characterized by accumulation of low density lipoprotein (LDL) in the artery wall. The transport of LDL across the endothelium of coronary artery is an initiating event of atherosclerosis, whose mechanism remains poorly understood. In the last decade, it has been shown that in caveolin-1 (Cav-1) deficient mice, LDL infiltration in aorta wall is decreased and CD36 expression in aortas is down-regulated, leading to regression of atherosclerotic lesions. In the present study, we show that native LDL endocytosis is decreased in endothelial cells deficient in Cav-1 or CD36. We demonstrate that Cav-1 and CD36 interact in caveolae-rich domains by different biochemical approaches. In addition, confocal microscopy reveals some colocalization of Cav-1 with CD36. These findings indicate that caveolae and CD36 are involved in native LDL endocytosis and suggest that CD36 might be a good candidate for the transport of native LDL across the endothelium, an early event in atherosclerosis.
\end{abstract}

\title{
Abbreviations:
}

Cav-1, Caveolin-1; GAPDH, Glyceraldehyde 3-phosphate dehydrogenase; LDL, low density lipoprotein.

\section{Keywords:}

Caveolin-1; CD36; endothelial cells; LDL; atherosclerosis. 


\section{Introduction}

Cardiovascular diseases are the first cause of mortality worldwide, and atherosclerosis is the main contributor to these diseases. Atherosclerosis is characterized by the formation of plaques that develop in the artery wall $[1,2]$. At the early stages of this disease, native LDL enters the arterial subendothelial intima where it accumulates and becomes oxidized, leading to the formation of plaques [3]. Although this early step is crucial for the development of the disease, the mechanism by which native LDL is transported through the endothelium of the arteries remains to be understood. Because of the small intercellular distance, the transport of LDL molecules across an intact endothelium is expected to be transcellular rather than paracellular [4].

Caveolae, first described as small plasma membrane invaginations [5], are microdomains enriched in sphingolipids, cholesterol and the major protein caveolin $[6,7]$. The isoform caveolin-1 (Cav-1) is highly expressed in endothelial cells, and is essential for caveolae formation [8,9], as its oligomerization is supposed to drive membrane curvature formation and inward invaginations. Caveolae have been shown to mediate transcytosis of albumin [10-13] via a specific receptor gp60 [14]. Native LDL transcytosis has been investigated for decades and several studies have suggested the involvement of caveolae in its transport across the endothelium. Indeed, endocytosis of perfused native LDL into rat aorta or coronary artery is mostly receptor-mediated and its transcytosis across endothelium occurs mainly via plasmalemmal vesicles [15]. Recently, it was reported that LDL endocytosis within Cav-1-deficient endothelial cells was lower than in normal cells, supporting a role of caveolae in LDL transcytosis [16]. Moreover, the involvement of Cav-1 in atherosclerosis in vivo has been demonstrated. Indeed, mice lacking Cav-1 presented $70 \%$ reduction of atheromatous lesions and reduced LDL infiltration into the artery wall, whereas expressing 
recombinant endothelial Cav-1 in these mice reversed both effects $[17,18]$. These two studies clearly establish that Cav-1 deficiency protects against atherosclerosis progression. If caveolae play an important role in the internalization of native LDL, it remains unclear which receptor is involved.

CD36 is a transmembrane glycoprotein that belongs to the family of scavenger receptors class B (SR-B), type 2 (SR-B2) [19]. It is expressed on different cell types including monocytes, platelets, adipocytes, macrophages, muscle cells and endothelial cells. It is well known that macrophages bind and internalize oxidized LDL via CD36 [20], leading to foam cell formation [21], a relatively late event in atherosclerosis. Besides, it has been shown that CD36 binds a large diversity of molecules, such as native lipoproteins in transfected cells [22], long chain fatty acids in adipocytes [23], in cardiac and skeletal muscle cells [24,25] and in liver cells [26,27], apoptotic cells in macrophages [28,29], and thrombospondin in endothelial cells [30,31], showing that there is not a unique ligand for CD36. Moreover, CD36 has been reported to be associated with both caveolae and non-caveolae domains. Thus, CD36 is localized within caveolae in adipocytes [32,33], in endothelium-enriched lung tissue [34], in fibroblasts [35], or in hepatic cells [36] .

Although it is clearly admitted that CD36 plays an important role in atherosclerosis as the receptor of oxidized LDL in macrophages [21], it is not known whether CD36 has a role in native LDL endocytosis. Therefore, we envisaged that CD36 could mediate native LDL endocytosis in endothelial cells and could contribute to the initiation of this disease.

In the present study, we demonstrate that native LDL endocytosis is decreased in human dermal lymphatic endothelial cells (HDLEC) deficient in Cav-1 or in CD36. We show that CD36 and Cav-1 interact in caveolae-rich domains. These results show that native LDL can be internalized via CD36 localized in caveolae. 


\section{MATERIALS AND METHODS}

\subsection{Materials}

Genistein and chlorpromazine were purchased from Calbiochem. Rabbit polyclonal antibody against Cav-1 was purchased from Abcam, mouse monoclonal antibody against CD36 was from Monosan, rabbit polyclonal antibody against GAPDH and control mouse isotype antibody were purchased from Santa-Cruz Biotechnology. Secondary antibodies antirabbit-HRP and anti-mouse-HRP were from Sigma, alexafluor-conjugated secondary antibodies, Tetramethylrhodamine-phalloidin (TRITC-phalloidin) were purchased from Invitrogen. ECL Prime Western Blot detection kit was from GE Healthcare. Fetal bovine serum (FBS), vascular endothelial growth factor, hydrocortisone, ascorbic acid, insulin like growth factor, basic fibroblast growth factor, epidermal growth factor and trypsin were purchased from Promocell. Phosphate Buffer Saline (PBS) was from Life Technologies and all other chemicals were from Sigma unless otherwise mentioned.

\subsection{Cell Culture}

HDLEC were purchased from Promocell and used at passages 4-5. Cells were seeded on cover slips or petri-dishes coated with $10 \mu \mathrm{g} / \mathrm{mL}$ fibronectin, at $50,000 \mathrm{cells} / \mathrm{cm}^{2}$ and cultivated for 2-3 days under $5 \% \mathrm{CO}_{2}$ atmosphere in a humidified incubator, at $37^{\circ} \mathrm{C}$, in endothelial cell basal medium-MV2 (Promocell), containing $5 \% \mathrm{FBS}, 0.5 \mathrm{ng} / \mathrm{ml}$ vascular endothelial growth factor, $0.2 \mu \mathrm{g} / \mathrm{ml}$ hydrocortisone, $1 \mu \mathrm{g} / \mathrm{ml}$ ascorbic acid, $20 \mathrm{ng} / \mathrm{ml} \mathrm{Insulin}$ like growth factor, $10 \mathrm{ng} / \mathrm{ml}$ basic fibroblast growth factor and $5 \mathrm{ng} / \mathrm{ml}$ epidermal growth factor (= complete medium), unless otherwise mentioned. 


\subsection{Immunofluorescence labeling.}

Cells were seeded on coverslips coated with fibronectin, at 50,000 cells $/ \mathrm{cm}^{2}$. Fortyeight hours later, they were fixed and stained for immunofluorescence at room temperature. Briefly, cells were fixed for 10 min with $4 \%$ paraformaldehyde in PBS, permeabilized for 5 min with $0.1 \%$ triton-X100 in PBS, washed then blocked for $1 \mathrm{~h} 30$ with $1 \%$ bovine serum albumin (BSA) in PBS. Next, cells were incubated with primary antibodies in PBS/BSA $0.2 \%$ for $1 \mathrm{~h}$ (mouse anti-CD36 1:200 and rabbit anti-Cav-1 1:300), then washed and incubated for 1h with secondary antibodies labeled with fluorescent probes (goat anti-mouse Alexa488 and donkey anti-rabbit Alexa546, 1:1000) antibodies in PBS/BSA 0.2\%. For negative control, the same procedure was performed but primary antibodies were omitted. After several washes, cells were mounted in Dako mounting medium.

\subsection{Colocalization analysis.}

Cells were cultured and immuno-stained for CD36 and Cav-1 as already described. Images were acquired with a Leica DMI6000 inverted TCS SP5 AOBS confocal microscope. Colocalization was quantified with the JACoP plugin installed in Image $\mathbf{J}$ software, by calculating the Manders' coefficients on all optical plans from a z-stack [37,38]. The Manders'coefficients were measured for each channel on thresholded images above background different from zero. A total of 25 cells were analyzed. Results are expressed as the mean percentage \pm SEM of Cav-1 colocalized with CD36, and conversely.

\subsection{Total Internal Reflection Fluorescence (TIRF) Microscopy.}

Cells were cultured and immuno-stained for CD36 or Cav-1 as already described, but cells were stored in PBS instead of mounting media. Images were acquired with a Nikon TiEclipse TIRF microscope coupled to a coherent laser. Emitted light was captured via a 100x, 
1.49 NA oil immersion objective and a EMCCD Photometrics Evolve camera. This same setup was used in epifluorescence experiments with LED lamp excitation instead of laser. Image analysis was performed with ImageJ software [38].

\subsection{Correlative Light and Electron Microscopy (CLEM).}

Cells were grown in MatTek glass bottom culture dishes (MatTek Corporation) at 1050 cells $/ \mathrm{cm}^{2}$. After 48 hours, cells were fixed in $4 \%$ paraformaldehyde in PBS for one hour at room temperature, then permeabilized using $0.1 \%$ saponin in PBS for 3 minutes. After thorough washing, cells were incubated 45 minutes in PBS/BSA $1 \%$ prior to incubation with rabbit anti-caveolin-1 antibody used at 1:500 in PBS/BSA $0.2 \%$ for 2 hours at room temperature. After several washes, cells were incubated with 1:100 dilution of anti-rabbit Alexa Fluor ${ }^{\circledR} * 488$-Fluoronanogold ${ }^{\mathrm{TM}}$ (Nanoprobes) in PBS/acetylated-BSA $0.1 \%$ for one hour at room temperature. The images in Light Microscopy were done with an inverted Leica DMI 6000 microscope equipped with a Leica DFC 350FX camera. Then, cells were fixed with $1 \%$ glutaraldehyde in PBS for 30 minutes and washed with distilled water followed by silver enhancement of gold using HQ SILVER ${ }^{\mathrm{TM}}$ (Nanoprobes). Cells were then postfixed with $1 \%$ Osmium tetraoxide in distilled water for 10 minutes at room temperature. Cells were then dehydrated in an ethanol series and embedded in LX-112 epoxy resin (Ladd). Ultrathin sections were stained with $2 \%$ uranyle acetate and Reynolds lead citrate. Observations were done with a CM120 TEM microscope (FEI) using 2k x 2k USC1000 slow-scan camera (Gatan). Image analysis was performed with Image J software.

\subsection{Protein extraction and Western-blot analysis.}

Cell monolayers were washed with ice-cold PBS and lysed at $4^{\circ} \mathrm{C}$ in lysis buffer (PBS/Triton X-100 1\%) containing protease inhibitor cocktail tablet (Roche). Cells were 
passed thru a 22 gauge needle 30 times and incubated on ice for 30 minutes. Then tritonresistant material was pelleted by centrifugation at $4^{\circ} \mathrm{C}$ for $15 \mathrm{~min}$ at $20,000 \mathrm{~g}$ (= Tritoninsoluble fraction). The supernatant was collected as the Triton-soluble fraction. In each sample, protein concentration was measured with the Protein Dc assay (Biorad) using BSA as a protein standard. Equal amounts of samples were loaded and run on a $10 \%$ sodium dodecyl sulfate polyacrylamide gel electrophoresis (SDS-PAGE), and fractionated proteins were transferred on to a polyvinylidene fluoride (PVDF) membrane (Immobilon, Merck). Membranes were blocked for $1 \mathrm{~h} 30$ at room temperature with 5\% (w/v) skimmed milk in Tris buffer saline (TBS: 50mMTris buffer, $\mathrm{pH} 8,138 \mathrm{mM} \mathrm{NaCl}$, and $2.7 \mathrm{mM} \mathrm{KCl}$ ) containing $0.1 \%$ Tween $20(=$ TBS-T) (for Cav-1 labeling) or with 5\% (w/v) skimmed milk in PBS containing $0.1 \%$ Tween 20 (= PBS-T) (for CD36 labeling). After washing in TBS-T or PBS$\mathrm{T}$, the membranes were incubated overnight at $4^{\circ} \mathrm{C}$ in TBS-T or PBS-T containing primary antibodies at appropriate concentrations in $1 \%(\mathrm{w} / \mathrm{v})$ skimmed milk. Antibody dilutions were used as follows: 1:4000 for caveolin 1, 1:500 for CD36, 1:1000 for GAPDH. The membranes were washed in TBS-T or PBS-T and incubated with peroxidase conjugated anti-rabbit $(1: 50,000)$ or anti-mouse (1:500) secondary antibodies. Immunoreactivity was revealed using ECL Prime detection kit according to the manufacturer instructions, and visualized with GeneGnome System (Syngene). Image J was used to quantify protein bands on immunoblots. Cav-1 and CD36 protein levels were corrected with GAPDH levels, as GAPDH was used as a loading control.

\subsection{Sucrose density fractionation.}

Caveolae were isolated as described previously [39] with minor modifications. Two $100 \mathrm{~mm}$ petri-dishes were used for each sucrose gradient. Cells were washed three times with ice-cold PBS and scraped. They were collected by centrifugation (1000g), and dispersed in a 
cold buffer solution (10 mM HEPES, pH 7.4, $1 \mathrm{mM} \mathrm{MgCl}_{2}, 1 \mathrm{mM}$ DTT, $5 \mathrm{mM} \mathrm{NaN}$ and protease inhibitor cocktail = buffer A) supplemented with $250 \mathrm{mM}$ sucrose. Cells were disrupted with a $22 \mathrm{G}$ needle (30 strokes) incubated on ice for 30 minutes. The homogenate was then adjusted to $45 \%$ sucrose by addition of $2.16 \mathrm{M}$ sucrose prepared in buffer A. The sample was transferred to the bottom of a $5 \mathrm{ml}$ centrifuge tube that contained two layers of $5 \%$ and $43 \%$ sucrose. After centrifugation $(17 \mathrm{~h}, 200,000 \mathrm{~g}$, in a Beckman MLS-50 rotor at $4^{\circ} \mathrm{C}$ ), ten fractions of $0.5 \mathrm{~mL}$ were collected from the top of the gradient to the bottom and stored for further analyses. Immuno-precipitation against CD36 was performed on F3 fraction (the caveolae fraction) as described below.

\subsection{Immuno-precipitation assay.}

Immuno-precipitation kit Dynabeads protein G (Invitrogen) was used according to the manufacturer instructions. Briefly, Dynabeads protein $\mathrm{G}$ were incubated for $30 \mathrm{~min}$ at room temperature with mouse anti-CD36, or rabbit anti-Cav-1 or control isotype antibodies. Then Dynabeads protein $\mathrm{G}$ covered with antibodies were washed three times with lysis buffer and mixed with protein sample (cell lysate, triton-soluble fraction or triton-insoluble fraction) for 30 minutes at room temperature. Immuno-precipitates were eluted with Laemmli buffer at $90^{\circ} \mathrm{C}$ for 5 minutes. Cells lysates or immuno-precipitates were analyzed by Western-blot for CD36 and Cav-1 as already described in Materials and Methods. Alternatively, immunoprecipitation was performed on sucrose gradient fractions.

\subsection{SiRNA transfection.}

Cav-1 Stealth RNAi siRNA (catalogue\# Cav1HSS141466), CD36 Stealth RNAi siRNA (catalogue\# CD36HSS101567), and their negative control Stealth RNAi siRNAs were purchased from Invitrogen. High GC Duplexes and medium GC Duplexes were used as 
negative controls for Cav-1 and CD36 respectively. In preliminary experiments, we optimized conditions for efficient down-regulation of the targeted genes using the minimal amount of siRNA with minimal cell toxicity. We found that optimal conditions for siRNA knock-down were as follows. 170000 cells were plated on 6-well plates coated with fibronectin and grown for $24 \mathrm{~h}$ hours in complete medium, where they reached $50 \%$ confluency. The next day, cells were washed once with Opti-MEM I reduced serum medium (Invitrogen) and transfected with $10 \mathrm{nM}$ siRNA and $3 \mu \mathrm{l}$ Lipofectamine RNAiMAX reagent (Invitrogen) in Opti-MEM I reduced serum medium. Six hours later, transfection medium was removed and complete medium was added to the cells that were then incubated for $48 \mathrm{~h}$. After this time, cells were ready to be collected and analyzed by western-blot for CD36 and Cav-1 expression (and GAPDH, used as a loading control), or used in native LDL endocytosis assay.

\subsection{LDL Endocytosis and flow cytometry.}

Cells were washed and exposed to $10 \mu \mathrm{g} / \mathrm{mL}$ native LDL-Dil (Invitrogen) in growth medium depleted in additives and serum, or without LDL-Dil for $1 \mathrm{~h}$ at $37^{\circ} \mathrm{C}$. Then cells were washed in ice-cold PBS, trypsinized and resuspended in cold PBS/BSA 0.5\%. Samples were analyzed on a BD Biosciences FACS Canto flow cytometer, as LDL-Dil was excited by a blue $488 \mathrm{~nm}$ laser. The analysis was performed using Diva software. A minimum of 5,000 events was recorded per sample. Cell debris were excluded, based on the forward and side scatter characteristics of cell populations.

\subsection{Shear stress experiments.}

Human coronary artery endothelial cells (HCAEC) (Lonza) were used at passages 3-4. They were seeded at 50000 cells $/ \mathrm{cm}^{2}$ under $5 \% \mathrm{CO}_{2}$ atmosphere in a humidified incubator, at $37^{\circ} \mathrm{C}$ in their endothelial basal medium EMB2, added with $5 \% \mathrm{FBS}, 0.4 \mu \mathrm{g} / \mathrm{mL}$ 
hydrocortisone, $4 \mu \mathrm{g} / \mathrm{mL}$ human fibroblast growth factor, $1 \mu \mathrm{g} / \mathrm{mL}$ vascular endothelial growth factor, $1 \mu \mathrm{g} / \mathrm{mL}$ R3-insulin growth factor-1, $1 \mu \mathrm{g} / \mathrm{mL}$ ascorbic acid, $1 \mu \mathrm{g} / \mathrm{mL}$ human epidermic growth factor, and antibiotics gentamycin and amphotericin GA-1000. The experimental laboratory set-up was homemade. It consisted of a flow chamber connected with pipes and valves to two bottles filled with culture medium (one used as a flow equalizer, the other one used as a culture medium reservoir). A peristaltic pump was inserted between both reservoirs in a closed circuit. HCAECs were cultured for 3 days on the surface of the flow chamber made of polydimethylsiloxane (VWR) coated with fibronectin. They were then submitted to shear stress for $24 \mathrm{~h}$. Control cells were cultured under static conditions for $24 \mathrm{~h}$. A $12 \mathrm{dyn} / \mathrm{cm}^{2}$ continuous linear shear stress was generated by the peristaltic pump [40]. After this period, cells were fixed and fluorescent immunostaining for CD36 was performed by anti-CD36 antibodies detected by alexa488-coupled secondary antibodies. Nuclei were labeled with $5 \mathrm{ng} / \mathrm{mL}$ Hoechst34580 (Invitrogen). Images were captured with an inverted Leica DMI 6000 microscope equipped with a Leica DFC 350FX camera.

\subsection{Statistics.}

Values are reported as their means \pm SEM, and are representative of an average of at least three independent experiments. Each independent experiment was conducted on a separate culture, made from one cell seeding. Comparisons between samples were performed using the student $t$-test. A p value $<0.05$ was considered significant. 


\section{RESULTS}

\subsection{Native LDL uptake is mediated by caveolae pathway in endothelial cells.}

Native LDL accumulation in the sub-endothelial space of arteries is the initial step of atherosclerosis. Therefore, we investigated the role of Cav-1 in native LDL endocytosis in HDLEC. First, we examined the uptake of native LDL in endothelial cells by flow cytometry, after treatment with chemical inhibitors, genistein and chlorpromazine, known to block caveolin and clathrin endocytic pathways, respectively. After 1h-pretreatment with either inhibitor, cells were incubated with fluorescently-labeled native LDL (LDL-Dil) and its endocytosis was quantified by flow cytometry. A significant reduction of native LDL endocytosis was observed in genistein-treated cells and in chlorpromazin-treated cells (40\% and 50\%, respectively) (Figure 1A). These results show that caveolae are significantly involved in native LDL endocytosis.

Then we challenged the cells with silencing interfering RNA (siRNA) in order to knock down Cav-1. Forty-eight hours after transfection, protein levels were analyzed by western-blot and quantified. Cav-1 protein levels were decreased by $58 \%$ in Cav-1 siRNA treated cells, as compared to cells treated with control siRNA (Figure 1B-C). In Cav-1 deficient cells, native LDL endocytosis was decreased by $60 \%$ as compared to control cells (Figure 1D).

Both results from chemical inhibitors or siRNA treatments indicate the involvement of caveolae endocytic pathway in native LDL transport. 

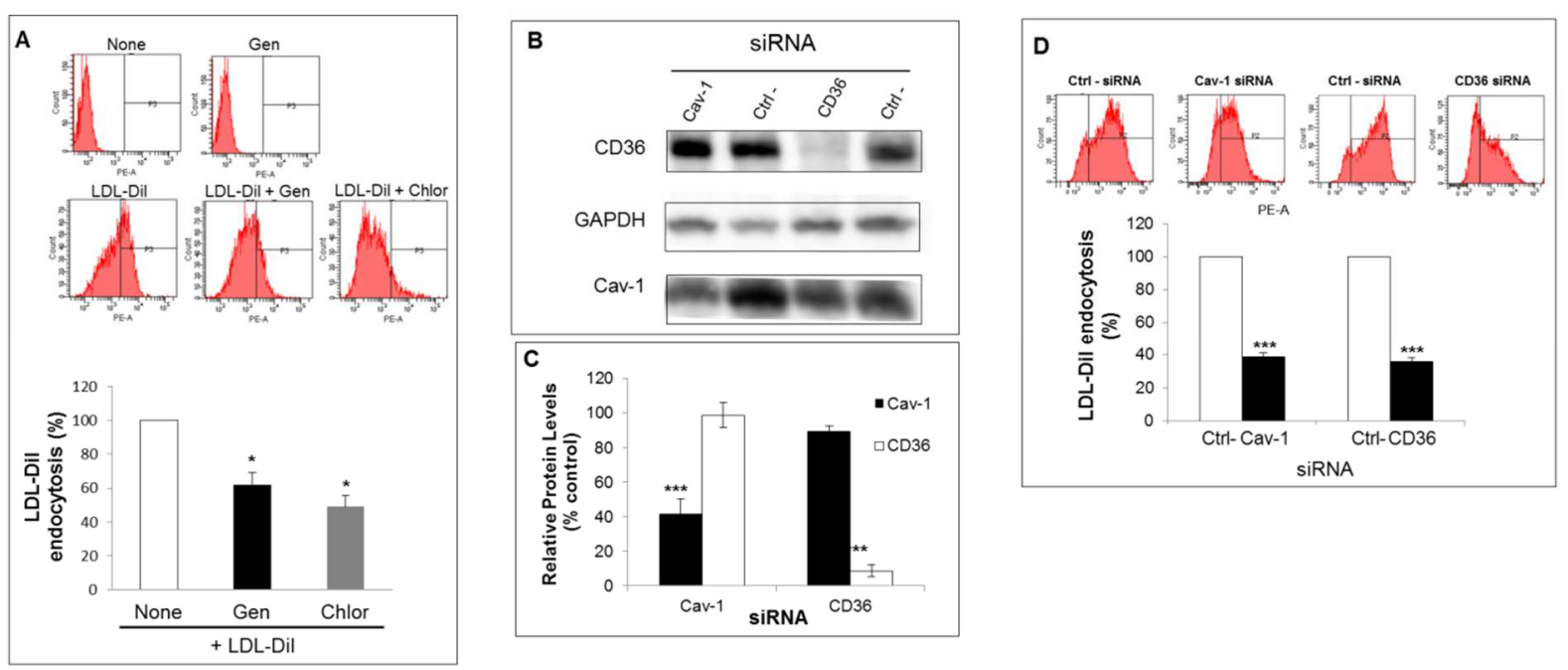

Figure 1: Caveolae and CD36-mediated endocytosis of LDL-Dil by HDLEC. (A) Cells were pre-incubated for $1 \mathrm{~h}$ with genistein $(200 \mu \mathrm{M})$ or chlorpromazine $(15 \mu \mathrm{M})$, or without any inhibitor, then LDL-Dil $(10 \mu \mathrm{g} / \mathrm{mL})$ was added for another $1 \mathrm{~h}$ and fluorescence quantified by flow cytometry. Cells that did not receive any treatment (= none) or only genistein (= Gen) are negative controls. Data analysis was performed with software FACSDiva. Results are expressed as a percent of endocytosed LDL-Dil in absence of inhibitors. Gen= genistein, Chlor $=$ chlorpromazine, $\mathrm{PE}=$ phycoerythrin $; * p<0.05, n=3$.

(B-D) HDLECs were treated with siRNA targeted to Cav-1 or to CD36 mRNA, or with scrambled siRNA as a control. Cav-1 protein or CD36 protein levels were analyzed by western-blot (B), and quantified using ImageJ software. Cav-1 and CD36 protein levels were normalized to GAPDH expression (C). Once specific protein deficiency for Cav-1 or CD36 was established, cells were added with LDL-Dil, and LDL-Dil endocytosis was quantified by flow cytometry. Results are expressed as a percentage of its own control (cells treated with scrambled siRNA for each gene) (D). $\quad * * * p<0.001, n \geq 3$. 


\subsection{Native LDL uptake is decreased in CD36 deficient endothelial cells.}

To assess the role of CD36 in native LDL transport, cells were treated with siRNA against CD36 in order to knock down its expression. Forty-eight hours after transfection, protein levels were quantified the same way as described for Cav-1 knock down experiments. CD36 protein expression was diminished by over $90 \%$ in CD36 siRNA treated cells, as compared to control siRNA treated cells (Figure 1B-C). Native LDL endocytosis was reduced by $65 \%$ in CD36 siRNA treated cells, as compared to control cells (Figure 1D).

It is noteworthy that neither Cav-1 nor CD36 expression was significantly affected in cells treated with CD36 siRNA or Cav-1 siRNA, respectively. Taken together, these results indicate that CD36 and Cav-1 are involved in the transport of native LDL uptake in HDLEC.

\subsection{Cav-1 and CD36 interact in caveolae-rich membrane domains.}

Then we investigated whether CD36 is associated with caveolae. Cells were lysed in a detergent-free buffer and the lysate was floated on a discontinuous sucrose gradient [39]. The sucrose gradient was fractionated into 10 fractions from top to bottom (F1 to F10 respectively) that were analyzed by western-blot using anti-Cav-1 IgG and anti-CD36 IgG. Results showed that Cav-1 was detected in the F3 and F4 fractions corresponding to the floated fractions between $5 \%$ and $43 \%$, associated with caveolae (Figure 2A). Cav-1 was also detected, but at lower levels, in fractions that contain non-raft membrane proteins and soluble proteins (F5 to F10). Most of CD36 was present in the F3 and F4 fractions.

We next examined if CD36 and Cav-1 present in the caveolae fraction could interact with each other. To serve that purpose, the F3 fraction was subjected to immuno-precipitation using an anti-CD36 IgG, and the precipitate was analyzed by western-blot (Figure 2B). Cav-1 was detected in the immuno-precipitate, proving the association of CD36 with caveolae in endothelial cells. Immunoblot analysis of F3 fraction immuno-precipitated with control 
antibody did not show the presence of neither CD36 nor Cav-1, confirming the interaction between Cav-1 and CD36 in the caveolae fraction.

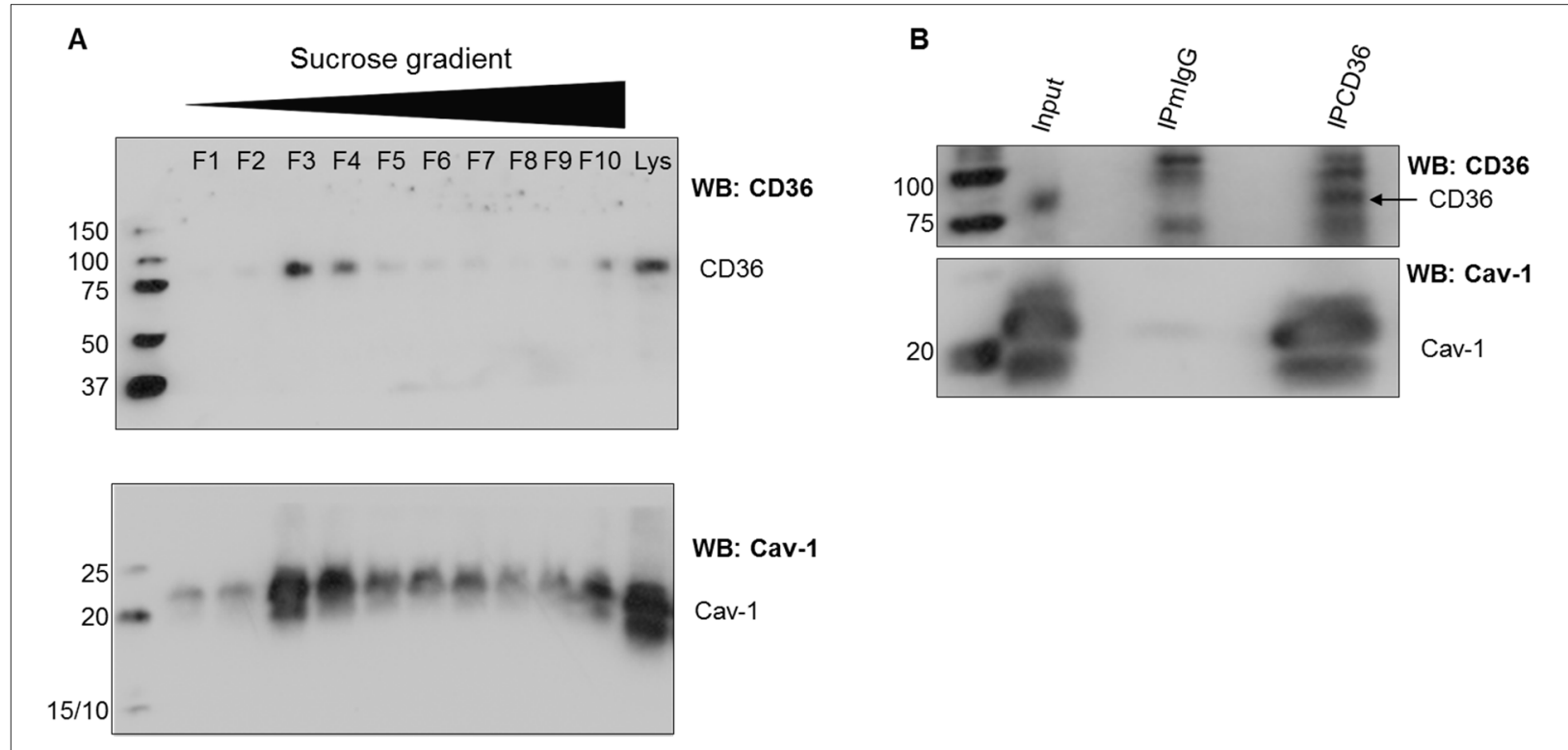

Figure 2: Interaction of Cav-1 and CD36 in caveolae-rich membrane domains isolated from HDLEC. (A) Sucrose gradient fractions were collected and analyzed by anti-CD36 and anti-Cav-1 immunoblotting. (B) Immunoprecipitation was performed on F3 fraction using a mouse IgG anti-CD36 or control mouse total $\mathrm{IgG}$ (mIgG). Lysates and immuno-precipitates were analyzed by Western-blot for CD36 and Cav-1, final detection performed by ECL. This shown experiment is representative of 3 independent experiments.

\subsection{Cav-1 and CD36 interact in Triton-insoluble fractions}

Caveolae are described as Triton-resistant microdomains [41]. Therefore, we investigated whether the interaction between CD36 and Cav-1 was preserved in the presence of Triton-X100. After cell homogenization in the presence of Triton X-100 at $4^{\circ} \mathrm{C}$, and centrifugation, both triton-soluble and triton-insoluble fractions were analyzed by Westernblot (Figure 3). CD36 and Cav-1 were detected in both fractions. However, immunoprecipitation with monoclonal mouse anti-CD36 IgG revealed that Cav-1 co-immuno- 
precipitated with CD36 only in the Triton-resistant fraction. In the Triton-soluble fraction, CD36 was immuno-precipitated but Cav-1 was not detected in the precipitate, although it was present in this fraction. Neither CD36 nor Cav-1 was detected when the triton-soluble fraction was incubated with isotype antibody.

Hence, accordingly to the sucrose gradient results, these data indicate that CD36 and Cav-1 are associated together in the detergent-resistant fraction that contains caveolae.

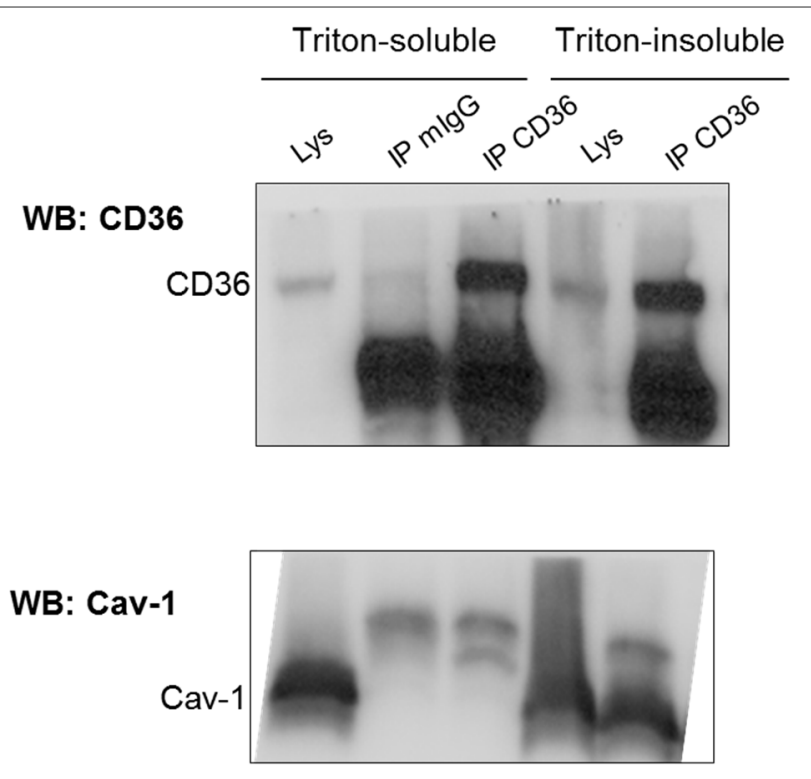

Figure 3: Interaction of Cav-1 and CD36 in Triton-insoluble fractions isolated from HDLEC. After lysis, the triton-resistant material was pelleted («Triton-insoluble» fraction) and the supernatant was collected as the «Triton-soluble» fraction. CD36 immunoprecipitation was performed as described in figure 2. Lysates and immuno-precipitates were separated by SDS-PAGE and analyzed by Western-blot for CD36 and Cav-1 and final detection performed by ECL. This shown experiment is representative of 3 independent experiments. 


\subsection{Distribution and colocalization of Cav-1 and CD36.}

To complement these biochemical results, we next evaluated the relative colocalization of CD36 and Cav-1 in cells, using confocal microscopy. Double immunostaining of Cav-1 with an Alexa546 (red) and CD36 with an Alexa488 (green), was performed. As shown in figure 4A, the merged images of all plans of both signals revealed an overlapping of CD36 and Cav-1. To quantify this overlapping, CD36 and Cav-1 colocalization was analyzed by calculating Manders' coefficients on thresholded images from all optical plans [37]. Results indicated that $30.4 \%( \pm 2.8)$ of Cav-1 colocalized with CD36 and $31.6 \%( \pm 1.4)$ of CD36 colocalized with Cav-1, suggesting a partial colocalization. These results support our biochemical data that CD36 is partially associated with caveolae. It is interesting to note that in siRNA experiments, we did not see any modification of CD36 distribution in cells treated with siRNA against Cav-1 (figure 4B). Therefore, in HDLEC, the absence of Cav-1 does not alter CD36 stabilization at cell membrane. 


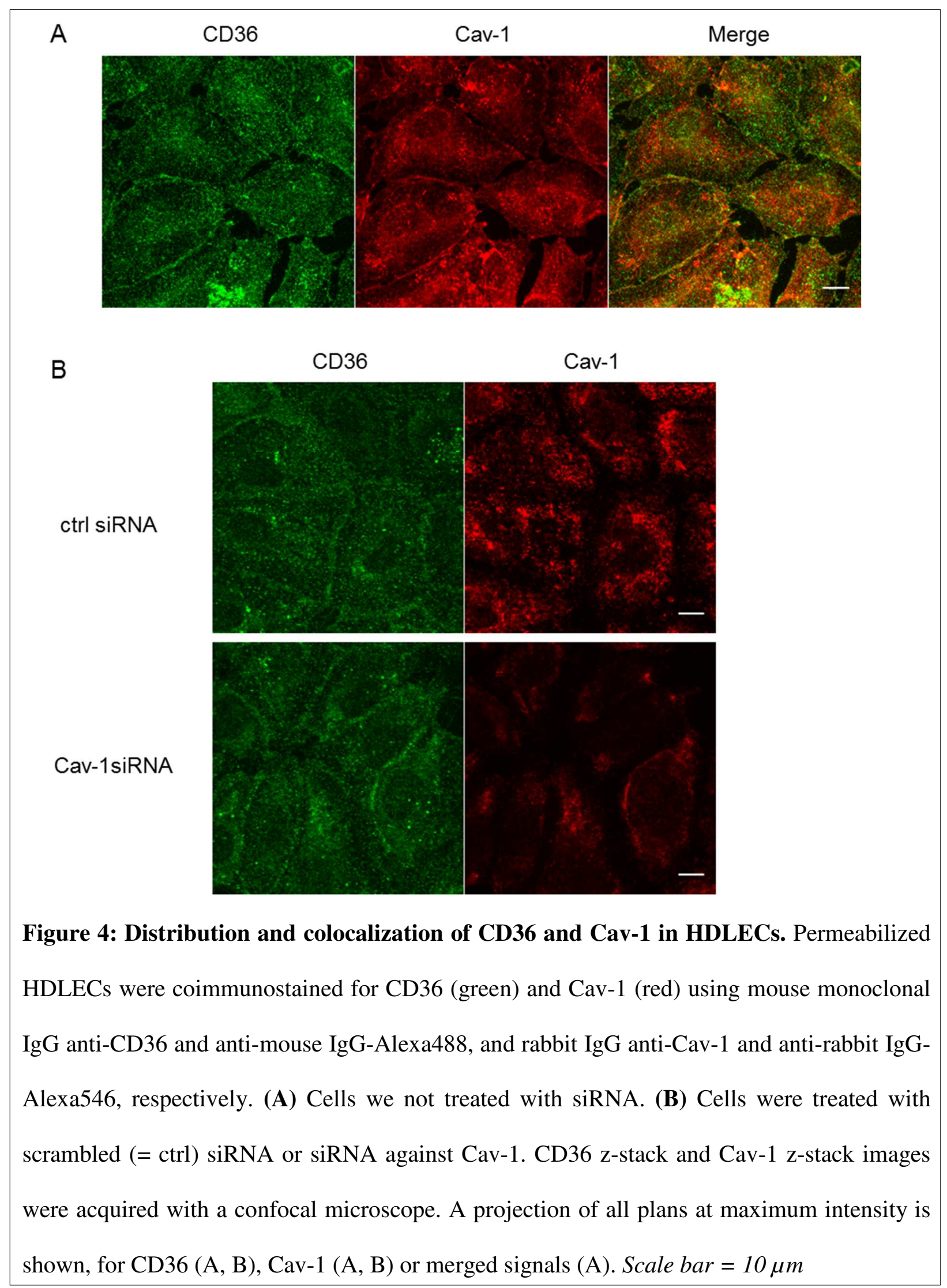




\subsection{Visualization of caveolae at the abluminal plasma membrane by EM and}

\section{TIR-FM.}

In order to visualize caveolae in our cultured endothelial cells, we performed CLEM experiments (Figure 5A). The immunofluorescent signal obtained for the localization of Cav1 using fluoronanoGold (FNG), exhibited small punctuate fluorescent patterns (Fig 5-A1). These patterns were further observed in ultrathin cell sections containing the plasma membrane (= first section close to the support) by electron microscopy (EM) (Fig5-A3). At higher magnification (Fig 5-A4), EM images revealed that sub-100 $\mathrm{nm}$ structures were surrounded by gold nanoparticles, confirming the presence of caveolae. To complement this result, TIR-FM experiments revealed that CD36 is not expressed at the abluminal side of the cells, whereas Cav-1 is clearly observed at the abluminal membrane (Figure 5B).

Altogether these results suggest that CD36 is more likely present at the luminal side of the cells. This is in agreement with our previous result on partial colocalization of Cav-1 and CD36. 


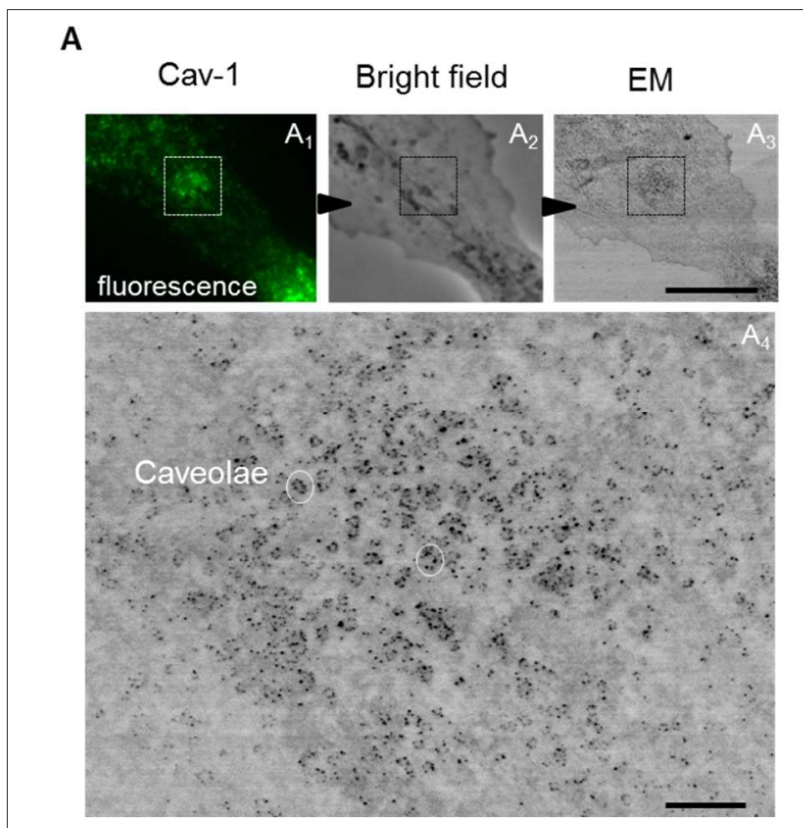

B

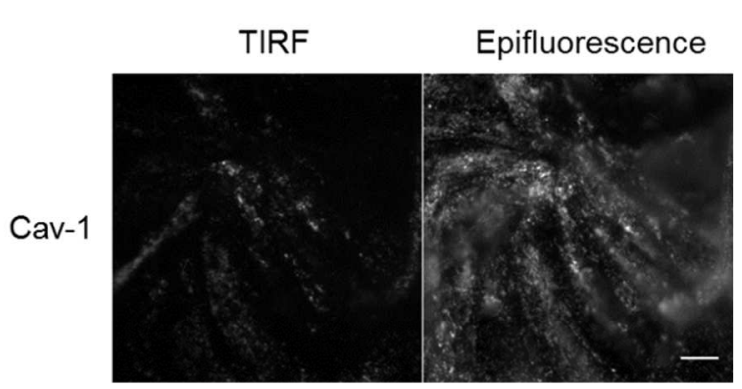

Figure 5: Visualization of caveolae at the plasma membrane. (A) CLEM. Cells grown in MatTek glass bottom culture dishes were immunostained for Cav-1 with anti-rabbit Alexa Fluor ${ }^{\circledR} * 488$-Fluoronanogold ${ }^{\mathrm{TM}}$. (A1, $\left.\mathbf{A} 2\right)$ Images in Light Microscopy were done with an epifluorescence microscope. (A3, A4) Then, silver enhancement of gold using HQ SILVER ${ }^{\mathrm{TM}}$ was performed and ultrathin sections were stained with $2 \%$ uranyl acetate. Observations were done with a TEM microscope. $\mathrm{EM}=$ electron microscopy. Upper scale bar $=10 \mu \mathrm{m}$, lower scale bar $=1 \mu \mathrm{m}$.

(B) TIR-FM. Cells were grown on fibronectin-coated $\mu$-dish, and CD36 and Cav-1 were labeled as described in figure 4 and stored in PBS until TIRF analysis. Prior to immunofluorescence staining, cells were fixed and permeabilized with Triton X-100. Epifluorescence and TIRF images are shown for each protein. The TIRF images show fluorescent signals present on the abluminal membrane. Each scale bar $=10 \mu \mathrm{m}$

\section{DISCUSSION AND CONCLUSION}

In this work, we investigated an initiating event in atherosclerosis, namely native LDL transcytosis through the endothelium. Two studies have suggested a role of endothelial Cav-1 
in the development of atherosclerosis in vivo [17,18]. However, in neither study was the receptor that binds native LDL, identified. For that matter, our study contributes to the elucidation of the mechanism by which native LDL would cross the endothelium of coronary artery, a crucial event in atherosclerosis progression. We show here the involvement of CD36 and caveolae in native LDL endocytosis in human endothelial cells. Indeed, we demonstrate that CD36 interacts with Cav-1 in endothelial cells, and that both proteins are involved in native LDL endocytosis, suggesting that CD36 might be a good candidate for the transport of native LDL across the endothelium. Our experiments using siRNA showed that native LDL uptake involved mainly CD36, and that residual LDL endocytosis may involve another receptor. LDL receptor (LDLR) is known to bind native LDL with high affinity [42], and has been reported to transport native LDL through the brain barrier endothelium [43]. However, we could not detect its presence by immunofluorescence analysis in our cultured cells, therefore we concluded that the LDLR was not responsible for this residual endocytosis. The absence of LDLR detection in our experiments is in agreement with reports that have shown that LDLR expression in cultured normal endothelial cell decreased with high cell density $[44,45]$. In diverse cell types, other receptors have been shown to mediate native LDL endocytosis. A recent study showed that SR-BI could transport native LDL across resting human coronary artery endothelial cells (HCAEC) via caveolae [46]. SR-BI is a class B scavenger receptor (type 1) closely related to CD36 [19]. Indeed, they share sequence similarity by $35 \%$ and even if SR-BI is best known to bind HDL, it can also bind other lipoproteins.

We showed that CD36 and Cav-1 are responsible for LDL endocytosis by $65 \%$ and $60 \%$ respectively, using siRNA against CD36 or Cav-1. We did not see any modification of CD36 distribution in Cav-1 deficient cells by IF analysis. This is a different observation from a study that showed cell membrane stabilization of CD36 by Cav-1 in MEF [35]. However, 
this relationship between Cav-1 and CD36 is somewhat controversial, as in primary hepatocytes or in hepatoma cells, CD36 is not stabilized at cell membrane by Cav-1 expression [26]. The dependence of CD36 availability at cell membrane on Cav-1 expression is probably cell type-specific. Indeed, CD36 can bind a large diversity of molecules depending on the cell type, leading to different cellular responses.

In our work, we used HDLEC because CD36 is constitutively expressed in resting HDLEC, whereas CD36 is weakly expressed in resting HCAEC. After submitting HCAEC to shear stress (a stimulus that mimics blood flow in arteries [40]), we observed increased CD36 expression and localization at the plasma membrane (Figure 6). In response to shear stress, cells aligned in the direction of the flow, and strechted out, as highlighted by F-actin labeling (Figure 6). These morphological changes in endothelial cells exposed to normal laminar flow have been reported in the literature [47].

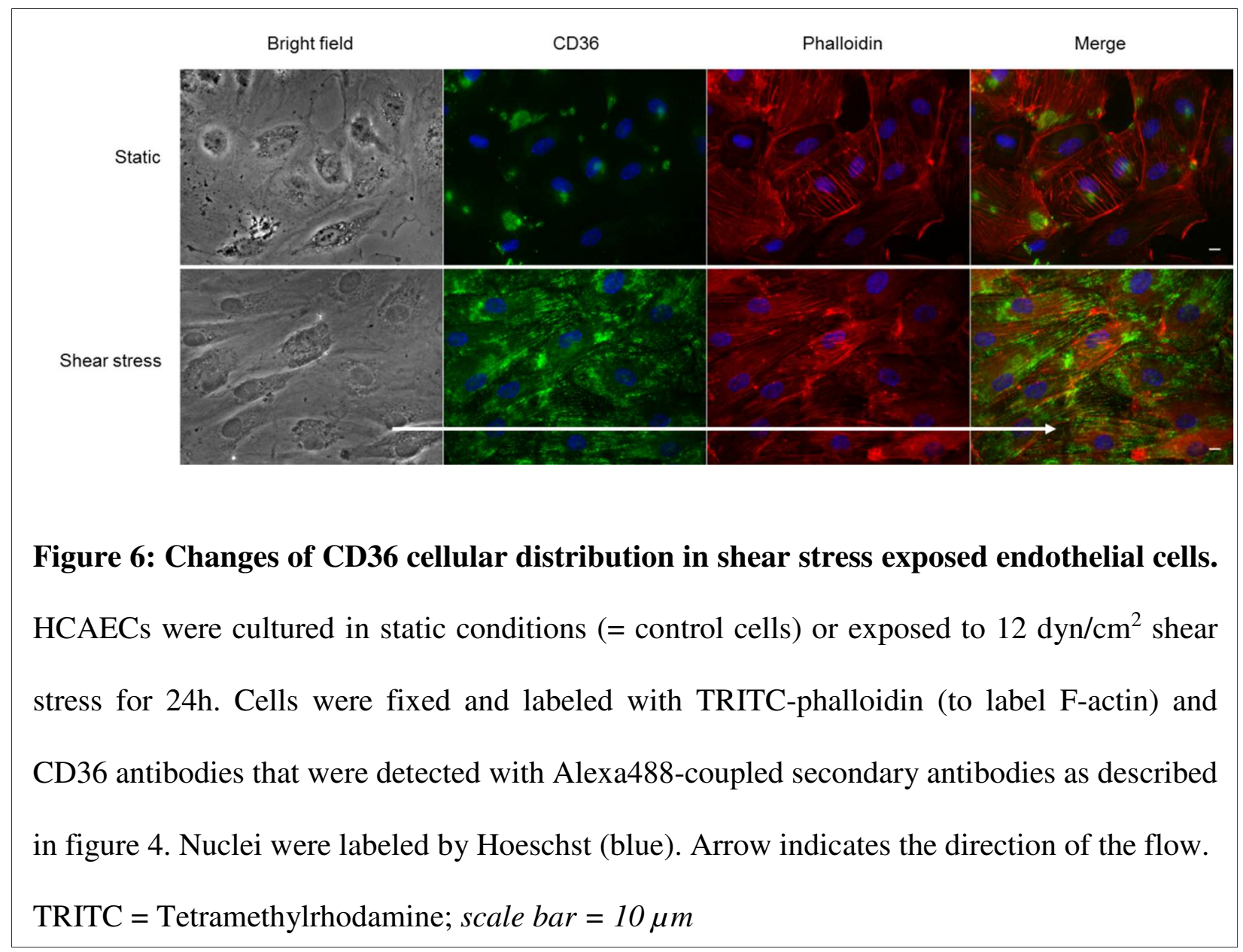


However, the set-up for shear-stress experiments with HCAEC was very delicate and inappropriate to conduct biochemical studies. Therefore, we worked with resting HDLEC expressing CD36 to investigate the role of CD36 in the mechanism responsible for native LDL endocytosis. It is conceivable that CD36 is involved in native LDL endocytosis in coronary arteries in vivo in the context of atherosclerosis, in agreement with the mechanism deciphered here in resting HDLEC. We showed that shear-stress modulates CD36 expression in HCAEC, suggesting that shear-stress could influence CD36 expression and LDL transport in vivo, depending on special regions of vasculature, where atheromatous plaques develop $[40,48]$. Furthermore, not only the coronary arteries are subject to atherosclerosis in vivo, but also carotid arteries, or leg arteries, pointing out the importance of the mechanism reported here in endothelial cells. This mechanism may be extended to other endothelial cell types in vivo.

We report that endogenous CD36 can mediate native LDL endocytosis in endothelial cells. It is well known that macrophage CD36 binds oxidized LDL and apoptotic cells in the artery wall, possibly via a mechanism involving caveolin-1 [28,49]. We show that native LDL endocytosis in endothelial cells occurs in a caveolae-dependent manner and involves CD36, suggesting a role for CD36 in native LDL transcytosis. Therefore, a new role for CD36 in caveolae should be considered: endocytosis of native LDL by endothelial cells which would result in retrieval of native LDL from the blood. Indeed, endothelial CD36 may be examined as a pharmaceutical target, to prevent progression of atherosclerosis. It is noteworthy that CD36 is largely described as a long chain fatty acid (LCFA) translocase in different cell types, such as adipocytes, muscle cells, enterocytes, or fibroblasts [50-54]. In muscle cells, LCFA are important substrates for energy synthesis as fatty acid oxidation contributes to ATP formation [25]. The exact molecular mechanism for LCFA uptake is not well understood and may depend on cell type. It involves different proteins whose relative contribution is still 
under investigation [55]. In this context, it was shown that Cav-1-stabilization of CD36 at cell membrane increased LCFA transport across plasma membrane in MEF [35]. While our study demonstrates that LDL endocytosis in endothelial cells is mediated by caveolae and CD36, reporting a new role for CD36.

In summary, we show here the involvement of CD36 and caveolae in native LDL endocytosis in human endothelial cells. LDL endocytosis is altered in cells deficient in cav-1 or in CD36. Both proteins are colocalized as shown by biochemical and microscopy methods. Transcytosis of lipoproteins is one initial event that involves native LDL but not oxidized LDL. Therefore, the transport of native LDL is crucial for the atherosclerosis outcome. Further experiments using a transwell culture system with Cav-1 or CD36 deficient cells should be developed to study the role of caveolae and CD36 in native LDL transcytosis.

\section{ACKNOWLEDGMENTS}

The authors are very thankful to Jacques Leng from the Laboratory Of the Future (LOF, Bordeaux) who helped us to develop the flow chamber and the whole set-up for shear-stress experiments. The authors also acknowledge the cytometry platform of University Bordeaux Segalen, and the Bordeaux Imaging Center for TIRF microscopy experiments. The microscopy was done in the Bordeaux Imaging Center a service unit of the CNRS-INSERM and Bordeaux University, member of the national infrastructure France BioImaging supported by the French National Research Agency (ANR-10-INBS-04). The help of Christel Poujol, Sébastien Marais and Fabrice Cordelières is acknowledged.

\section{FUNDING}

This work was funded by a grant from the University of Bordeaux ( $\mathrm{n}^{\circ} 2$ 2010). This work has been supported also in part by a grant from Conseil Régional d'Aquitaine ( $\left.n^{\circ} 20121301007\right)$. 


\section{REFERENCES}

[1] A.R. Tall, L. Yvan-Charvet, Cholesterol, inflammation and innate immunity, Nat. Rev. Immunol., 15 (2015) 104-116.

[2] P. Libby, Inflammation in Atherosclerosis, Arterioscler. Thromb. Vasc. Biol., 32 (2012) 2045-2051.

[3] I. Tabas, K.J. Williams, J. Boren, Subendothelial Lipoprotein Retention as the Initiating Process in Atherosclerosis: Update and Therapeutic Implications, Circulation, 116 (2007) 1832-1844.

[4] N. Simionescu, M. Simionescu, G.E. Palade, Open junctions in the endothelium of the postcapillary venules of the diaphragm, J. Cell Biol., 79 (1978) 27-44.

[5] G.E. Palade, Fine Structure of Blood Capillaries, J. Appl. Phys., (1953) 1424.

[6] K.G. Rothberg, J.E. Heuser, W.C. Donzell, Y.S. Ying, J.R. Glenney, R.G. Anderson, Caveolin, a protein component of caveolae membrane coats, Cell, 68 (1992) 673-682.

[7] R.V. Stan, Structure of caveolae, Biochim. Biophys. Acta BBA - Mol. Cell Res., 1746 (2005) 334348.

[8] M. Drab, P. Verkade, M. Elger, M. Kasper, M. Lohn, B. Lauterbach, J. Menne, C. Lindschau, F. Mende, F.C. Luft, A. Schedl, H. Haller, T.V. Kurzchalia, Loss of caveolae, vascular dysfunction, and pulmonary defects in caveolin-1 gene-disrupted mice, Science, 293 (2001) 2449-2452.

[9] P.M. Bauer, J. Yu, Y. Chen, R. Hickey, P.N. Bernatchez, R. Looft-Wilson, Y. Huang, F. Giordano, R.V. Stan, W.C. Sessa, Endothelial-specific expression of caveolin-1 impairs microvascular permeability and angiogenesis, Proc. Natl. Acad. Sci. U. S. A., 102 (2005) 204-209.

[10]J.E. Schnitzer, P. Oh, E. Pinney, J. Allard, Filipin-sensitive caveolae-mediated transport in endothelium: reduced transcytosis, scavenger endocytosis, and capillary permeability of select macromolecules, J. Cell Biol., 127 (1994) 1217-1232.

[11]W. Schubert, P.G. Frank, B. Razani, D.S. Park, C.-W. Chow, M.P. Lisanti, Caveolae-deficient Endothelial Cells Show Defects in the Uptake and Transport of Albumin in Vivo, J. Biol. Chem., 276 (2001) 48619-48622.

[12] D. Predescu, S.M. Vogel, A.B. Malik, Functional and morphological studies of protein transcytosis in continuous endothelia, Am. J. Physiol.-Lung Cell. Mol. Physiol., 287 (2004) L895-L901.

[13]A. Filippini, G. Sica, A. D'Alessio, The caveolar membrane system in endothelium: From cell signaling to vascular pathology, J. Cell. Biochem., (2018).

[14] R.D. Minshall, C. Tiruppathi, S.M. Vogel, W.D. Niles, A. Gilchrist, H.E. Hamm, A.B. Malik, Endothelial cell-surface gp60 activates vesicle formation and trafficking via Gi-coupled Src kinase signaling pathway, J. Cell Biol., 150 (2000) 1057-1070.

[15]E. Vasile, M. Simionescu, N. Simionescu, Visualization of the binding, endocytosis, and transcytosis of low-density lipoprotein in the arterial endothelium in situ, J. Cell Biol., 96 (1983) 1677-1689.

[16] S. Pavlides, J.L. Gutierrez-Pajares, J. Iturrieta, M.P. Lisanti, P.G. Frank, Endothelial caveolin-1 plays a major role in the development of atherosclerosis, Cell Tissue Res., 356 (2014) 147-157.

[17]P.G. Frank, Genetic Ablation of Caveolin-1 Confers Protection Against Atherosclerosis, Arterioscler. Thromb. Vasc. Biol., 24 (2004) 98-105.

[18] C. Fernández-Hernando, J. Yu, Y. Suárez, C. Rahner, A. Dávalos, M.A. Lasunción, W.C. Sessa, Genetic Evidence Supporting a Critical Role of Endothelial Caveolin-1 during the Progression of Atherosclerosis, Cell Metab., 10 (2009) 48-54.

[19] M. PrabhuDas, D. Bowdish, K. Drickamer, M. Febbraio, J. Herz, L. Kobzik, M. Krieger, J. Loike, T.K. Means, S.K. Moestrup, S. Post, T. Sawamura, S. Silverstein, X.-Y. Wang, J. El Khoury, Standardizing Scavenger Receptor Nomenclature, J. Immunol. Baltim. Md 1950, 192 (2014) 1997-2006.

[20] G. Endemann, L.W. Stanton, K.S. Madden, C.M. Bryant, R.T. White, A.A. Protter, CD36 is a receptor for oxidized low density lipoprotein, J. Biol. Chem., 268 (1993) 11811-11816.

[21] S.O. Rahaman, D.J. Lennon, M. Febbraio, E.A. Podrez, S.L. Hazen, R.L. Silverstein, A CD36dependent signaling cascade is necessary for macrophage foam cell formation, Cell Metab., 4 (2006) 211-221. 
[22] D. Calvo, D. Gómez-Coronado, Y. Suárez, M.A. Lasunción, M.A. Vega, Human CD36 is a high affinity receptor for the native lipoproteins HDL, LDL, and VLDL, J. Lipid Res., 39 (1998) 777-788.

[23] A.G.S. Baillie, C.T. Coburn, N.A. Abumrad, Reversible binding of long-chain fatty acids to purified FAT, the adipose CD36 homolog, J. Membr. Biol., 153 (1996) 75-81.

[24] F.A. Van Nieuwenhoven, C.P. Verstijnen, N.A. Abumrad, P.H. Willemsen, G.J. Van Eys, G.J. Van der Vusse, J.F. Glatz, Putative membrane fatty acid translocase and cytoplasmic fatty acidbinding protein are co-expressed in rat heart and skeletal muscles, Biochem. Biophys. Res. Commun., 207 (1995) 747-752.

[25] A. Ibrahimi, A. Bonen, W.D. Blinn, T. Hajri, X. Li, K. Zhong, R. Cameron, N.A. Abumrad, Musclespecific overexpression of FAT/CD36 enhances fatty acid oxidation by contracting muscle, reduces plasma triglycerides and fatty acids, and increases plasma glucose and insulin, J. Biol. Chem., 274 (1999) 26761-26766.

[26] N.S. Eyre, L.G. Cleland, N.N. Tandon, G. Mayrhofer, Importance of the carboxyl terminus of FAT/CD36 for plasma membrane localization and function in long-chain fatty acid uptake, J. Lipid Res., 48 (2007) 528-542.

[27]X. Zhang, R.L. Fitzsimmons, L.G. Cleland, P.L. Ey, A.C.W. Zannettino, E.-A. Farmer, P. Sincock, G. Mayrhofer, CD36/Fatty Acid Translocase in Rats: Distribution, Isolation from Hepatocytes, and Comparison with the Scavenger Receptor SR-B1, Lab. Invest., 83 (2003) 317-332.

[28] M. Ferracini, F.J.O. Rios, M. Pecenin, S. Jancar, Clearance of Apoptotic Cells by Macrophages Induces Regulatory Phenotype and Involves Stimulation of CD36 and Platelet-Activating Factor Receptor, Mediators Inflamm., 2013 (2013) 1-8.

[29] M.-K. Chang, C. Bergmark, A. Laurila, S. Hörkkö, K.-H. Han, P. Friedman, E.A. Dennis, J.L. Witztum, Monoclonal antibodies against oxidized low-density lipoprotein bind to apoptotic cells and inhibit their phagocytosis by elicited macrophages: evidence that oxidation-specific epitopes mediate macrophage recognition, Proc. Natl. Acad. Sci., 96 (1999) 6353-6358.

[30] D.W. Dawson, S.F. Pearce, R. Zhong, R.L. Silverstein, W.A. Frazier, N.P. Bouck, CD36 mediates the In vitro inhibitory effects of thrombospondin-1 on endothelial cells, J. Cell Biol., 138 (1997) 707717.

[31] B. Jiménez, O.V. Volpert, S.E. Crawford, M. Febbraio, R.L. Silverstein, N. Bouck, Signals leading to apoptosis-dependent inhibition of neovascularization by thrombospondin-1, Nat. Med., 6 (2000) 41-48.

[32] R.P. Souto, G. Vallega, J. Wharton, J. Vinten, J. Tranum-Jensen, P.F. Pilch, Immunopurification and Characterization of Rat Adipocyte Caveolae Suggest Their Dissociation from Insulin Signaling, J. Biol. Chem., 278 (2003) 18321-18329.

[33] J. Pohl, A. Ring, U. Korkmaz, R. Ehehalt, W. Stremmel, FAT/CD36-mediated long-chain fatty acid uptake in adipocytes requires plasma membrane rafts, Mol. Biol. Cell, 16 (2005) 24-31.

[34] M.P. Lisanti, P.E. Scherer, J. Vidugiriene, Z. Tang, A. Hermanowski-Vosatka, Y.H. Tu, R.F. Cook, M. Sargiacomo, Characterization of caveolin-rich membrane domains isolated from an endothelialrich source: implications for human disease, J. Cell Biol., 126 (1994) 111-126.

[35] A. Ring, S. Le Lay, J. Pohl, P. Verkade, W. Stremmel, Caveolin-1 is required for fatty acid translocase (FAT/CD36) localization and function at the plasma membrane of mouse embryonic fibroblasts, Biochim. Biophys. Acta, 1761 (2006) 416-423.

[36]T.Q. Truong, M.R. Brodeur, L. Falstrault, D. Rhainds, L. Brissette, Expression of caveolin-1 in hepatic cells increases oxidized LDL uptake and preserves the expression of lipoprotein receptors, J. Cell. Biochem., 108 (2009) 906-915.

[37]S. Bolte, F.P. Cordelières, A guided tour into subcellular colocalization analysis in light microscopy, J. Microsc., 224 (2006) 213-232.

[38] C.A. Schneider, W.S. Rasband, K.W. Eliceiri, NIH Image to ImageJ: 25 years of image analysis, Nat. Methods, 9 (2012) 671-675.

[39] S. Goudenege, S. Poussard, S. Dulong, P. Cottin, Biologically active milli-calpain associated with caveolae is involved in a spatially compartmentalised signalling involving protein kinase $\mathrm{C}$ alpha 
and myristoylated alanine-rich C-kinase substrate (MARCKS), Int. J. Biochem. Cell Biol., 37 (2005) 1900-1910.

[40] Y.S. Chatzizisis, A.U. Coskun, M. Jonas, E.R. Edelman, C.L. Feldman, P.H. Stone, Role of endothelial shear stress in the natural history of coronary atherosclerosis and vascular remodeling: molecular, cellular, and vascular behavior, J. Am. Coll. Cardiol., 49 (2007) 23792393.

[41] E. London, D.A. Brown, Insolubility of lipids in triton X-100: physical origin and relationship to sphingolipid/cholesterol membrane domains (rafts), Biochim. Biophys. Acta, 1508 (2000) 182195.

[42] J.L. Goldstein, M.K. Sobhani, J.R. Faust, M.S. Brown, Heterozygous familial hypercholesterolemia: failure of normal allele to compensate for mutant allele at a regulated genetic locus, Cell, 9 (1976) 195-203.

[43] B. Dehouck, L. Fenart, M.-P. Dehouck, A. Pierce, G. Torpier, R. Cecchelli, A new function for the LDL receptor: transcytosis of LDL across the blood-brain barrier, J. Cell Biol., 138 (1997) 877-889.

[44] I. Vlodavsky, P.E. Fielding, L.K. Johnson, D. Gospodarowicz, Inhibition of low density lipoprotein uptake in confluent endothelial cell monolayers correlates with a restricted surface receptor redistribution, J. Cell. Physiol., 100 (1979) 481-495.

[45] R. Kenagy, E.L. Bierman, S. Schwartz, J.J. Albers, Metabolism of low density lipoprotein by bovine endothelial cells as a function of cell density, Arterioscler. Dallas Tex, 4 (1984) 365-371.

[46] S.M. Armstrong, M.G. Sugiyama, K.Y.Y. Fung, Y. Gao, C. Wang, A.S. Levy, P. Azizi, M. Roufaiel, S.N. Zhu, D. Neculai, C. Yin, S.-S. Bolz, N.G. Seidah, M.I. Cybulsky, B. Heit, W.L. Lee, A novel assay uncovers an unexpected role for SR-BI in LDL transcytosis, Cardiovasc. Res., 108 (2015) 268-277.

[47] P.F. Davies, Flow-mediated endothelial mechanotransduction, Physiol. Rev., 75 (1995) 519-560.

[48] C. Hahn, M.A. Schwartz, Mechanotransduction in vascular physiology and atherogenesis, Nat. Rev. Mol. Cell Biol., 10 (2009) 53-62.

[49] R.F. Collins, N. Touret, H. Kuwata, N.N. Tandon, S. Grinstein, W.S. Trimble, Uptake of Oxidized Low Density Lipoprotein by CD36 Occurs by an Actin-dependent Pathway Distinct from Macropinocytosis, J. Biol. Chem., 284 (2009) 30288-30297.

[50] A. Bonen, D.J. Dyck, A. Ibrahimi, N.A. Abumrad, Muscle contractile activity increases fatty acid metabolism and transport and FAT/CD36, Am. J. Physiol., 276 (1999) E642-649.

[51] S. Nozaki, T. Tanaka, S. Yamashita, K. Sohmiya, T. Yoshizumi, F. Okamoto, Y. Kitaura, C. Kotake, H. Nishida, A. Nakata, T. Nakagawa, K. Matsumoto, K. Kameda-Takemura, S. Tadokoro, Y. Kurata, Y. Tomiyama, K. Kawamura, Y. Matsuzawa, CD36 mediates long-chain fatty acid transport in human myocardium: complete myocardial accumulation defect of radiolabeled long-chain fatty acid analog in subjects with CD36 deficiency, Mol. Cell. Biochem., 192 (1999) 129-135.

[52] C.T. Coburn, F.F. Knapp, M. Febbraio, A.L. Beets, R.L. Silverstein, N.A. Abumrad, Defective Uptake and Utilization of Long Chain Fatty Acids in Muscle and Adipose Tissues of CD36 Knockout Mice, J. Biol. Chem., 275 (2000) 32523-32529.

[53] A. Ibrahimi, Z. Sfeir, H. Magharaie, E.-Z. Amri, P. Grimaldi, N.A. Abumrad, Expression of the CD36 homolog (FAT) in fibroblast cells: effects on fatty acid transport, Proc. Natl. Acad. Sci., 93 (1996) 2646-2651.

[54] C.T. Coburn, T. Hajri, A. Ibrahimi, N.A. Abumrad, Role of CD36 in membrane transport and utilization of long-chain fatty acids by different tissues, J. Mol. Neurosci. MN, 16 (2001) 117-121; discussion 151-157.

[55] B.R. Thompson, S. Lobo, D.A. Bernlohr, Fatty acid flux in adipocytes: the in's and out's of fat cell lipid trafficking, Mol. Cell. Endocrinol., 318 (2010) 24-33. 